\title{
Snow Cover Detection Based on Visible Red and Blue Channel from MODIS Imagery Data
}

\author{
Paipai Pan1, Guoyue Chen², Kazuki Saruta², Yuki Terata ${ }^{2}$ \\ ${ }^{1}$ Graduate School of Systems Science and Technology, Integrated Course of Systems Science and Technology, \\ Akita Prefectural University, Yurihonjo City, Japan \\ ${ }^{2}$ Department of Electronics and Information Systems, Akita Prefectural University, Yurihonjo City, Japan \\ Email: d14s003@akita-pu.ac.jp
}

Received 2 January 2015; accepted 25 January 2015; published 28 January 2015

Copyright (c) 2015 by authors and Scientific Research Publishing Inc.

This work is licensed under the Creative Commons Attribution International License (CC BY). http://creativecommons.org/licenses/by/4.0/

(c) (i) Open Access

\begin{abstract}
In the present work, a new snow cover detection method based on visible red and blue bands from MODIS imagery data is proposed for Akita prefecture under the sunny cloud-free conditions. Before the snow cover detection, the MODIS imagery of the study area is pre-processed by geographic correction, clipping, atmospheric correction and topographic correction. Snow cover detection is carried out by applying the reflectance similarities of snow and other substances in the visible red band 1 and blue band 3 . Then, the threshold values are confirmed to distinguish snow pixels from other substances by analyzing the composited true color images and 2-dimensional scatter plots. The MOD10_L2 products and in-situ snow depth data from 31 observation stations across the whole study area are chosen to compare and validate the effectivity of proposed method for snow cover detection. We calculate the overall accuracy, over-estimation error and under-estimation error of snow cover detection during the snowy season from May 2012 to April 2014, and the results are compared by classifying all of the observation stations into forest areas, basin areas and plain areas. It proves that the snow cover can be detected effectively in Akita prefecture by the proposed method. And the average overall accuracy of proposed method is higher than MOD10_L2 product, improved by $26.27 \%$. The proposed method is expected to improve the environment management and agricultural development for local residents.
\end{abstract}

\section{Keywords}

Akita, MODIS, Remote Sensing, Snow Cover

\section{Introduction}

Snow, as a part of the earth's hydrosphere, is one of the most important input parameters in the global energy

How to cite this paper: Pan, P.P., Chen, G.Y., Saruta, K. and Terata, Y. (2015) Snow Cover Detection Based on Visible Red and Blue Channel from MODIS Imagery Data. International Journal of Geosciences, 6, 51-66.

http://dx.doi.org/10.4236/ijg.2015.61004 
balance, climate, hydrological and ecological models. It has been an important factor on the global climate changes [1]. Snow cover detection (SCD) cannot only improve the management of regional water resources effectively, but also contribute to the ecological environment construction, environment protection and agricultural production [2]. Therefore, it is very important to study the snow cover conditions and their effects on the global climate.

Previously, the SCD was conducted with ground observation station. Its detected result is real and objective. However, due to the uneven distribution of ground observation stations, inevitable mistakes and missing make the accuracy cannot meet the requirement of certain research [3]. With the rapid development of satellite remote sensing technology, the SCD using earth observation satellite images has become a more effective method. It can obtain the information of snow cover distribution timely and accurately. Snow can be clearly distinguished from other substances exclude cloud because its reflectance is very high [4]. It is for this important reason that satellite remote sensing data are very suitable for the SCD.

So far, most of researches on the SCD base on Landsat [5], NOAA [6] and MODIS [7] satellite image data. By far, the most mature and effective method is the MODIS snow cover product [8] [9]. It is the most effective optical sensor snow inversion algorithm and has been commercialized. MODIS snow cover product mainly bases on the differences of surface reflectance between snow and other substances in different spectral ranges [10]. The SCD and analysis is conducted by threshold value measurement, normalized identification between bands, ratio calculation between shortwave infrared and visible light. The most typical snow cover recognition algorithm is Normalized Difference Snow Index (NDSI) [7] [11]. However, it has been proved that there are lots of errors for the SCD due to the under-estimation with this method.

The SCD in mountains and forests can be affected by atmosphere, terrain and snow covered underlying surface [12]. Therefore, in this work, the pre-processing including geographic correction, clipping, atmospheric correction and topographic correction is conducted to get real surface reflectance. The reflectance construction similarity of snow and other substances in the visible red band 1 and blue band 3 of MODIS image is applied in order to more effectively detect the snow cover. Furthermore, we observed the 5 typical images of clear days during the whole year, and confirmed the threshold values by investigating these 5 typical images and their corresponding 2-dimensional scatter plots in bands 1 and 3. Finally, the SCD results of the study area are obtained.

\section{Study Area and Data}

\subsection{Study Area}

The Akita prefecture with a total area of $11636.32 \mathrm{~km}^{2}$ (http://uub.jp/47/akita) locates in the northeast of Honshu which is the main island of Japan as shown in Figure 1. Its coordinates of the latitude and longitude are between $38^{\circ} 52^{\prime} 23^{\prime \prime} \mathrm{N}$ and $40^{\circ} 30^{\prime} 40^{\prime \prime} \mathrm{N}$, and $139^{\circ} 41^{\prime} 32^{\prime \prime} \mathrm{E}$ and $140^{\circ} 59^{\prime} 43^{\prime \prime} \mathrm{E}$

(http://www.gsi.go.jp/KOKUJYOHO/CENTER/kendata/akita_heso.htm). The region has a coast with the Sea of Japan in the west and is bordered by four other prefectures: Aomori in the north, Iwate in the east, Miyagi in the southeast and Yamagata in the south (http://www.pref.akita.jp/koho/foreign/en/0010.html).

Akita prefecture is the typical climate of the Sea of Japan, winter is long and summer is short. Its four seasons are distinct. Winter is very cold with short frost-free period, and summer is hot with less sunshine and abundant rainfall, the annual rainfall is about $1800 \mathrm{~mm}$ (http://www.data.jma.go.jp/gmd/risk/obsdl/index.php). The warm and cold Tsushima currents result in significant amounts of snowfall in Akita prefecture during the winter, with annual snowfall around $377 \mathrm{~cm}$. The general average thickness of the snow is $48 \mathrm{~cm}$. And the maximum and minimum temperature during the snowy season are $-4.82^{\circ} \mathrm{C}$ and $-11.26^{\circ} \mathrm{C}$, respectively. The terrain of Akita prefecture is high in east and low in west. There are the Ou Mountains in the east boundary, and the Dewa Mountains with basins in the central, and coastal plains in the western. Due to the Dewa Mountains run parallel cross the central region of the prefecture, the whole region has been divided into two big areas, their climates are different. There are often a lot of snow cover in inland and few snow cover in coastal area

(http://www.jma-net.go.jp/akita/4season/4season.htm).

Due to sparsely populated and almost no industrial in the Akita prefecture, rice planting in agricultural production is very developed and ranked third in Japan. In addition, more than $70 \%$ is covered by forests in the whole prefecture. The majority forests are coniferous and deciduous, and account for around $54.71 \%$ and $41.48 \%$ of the forested area in the whole prefecture, respectively [13]. 

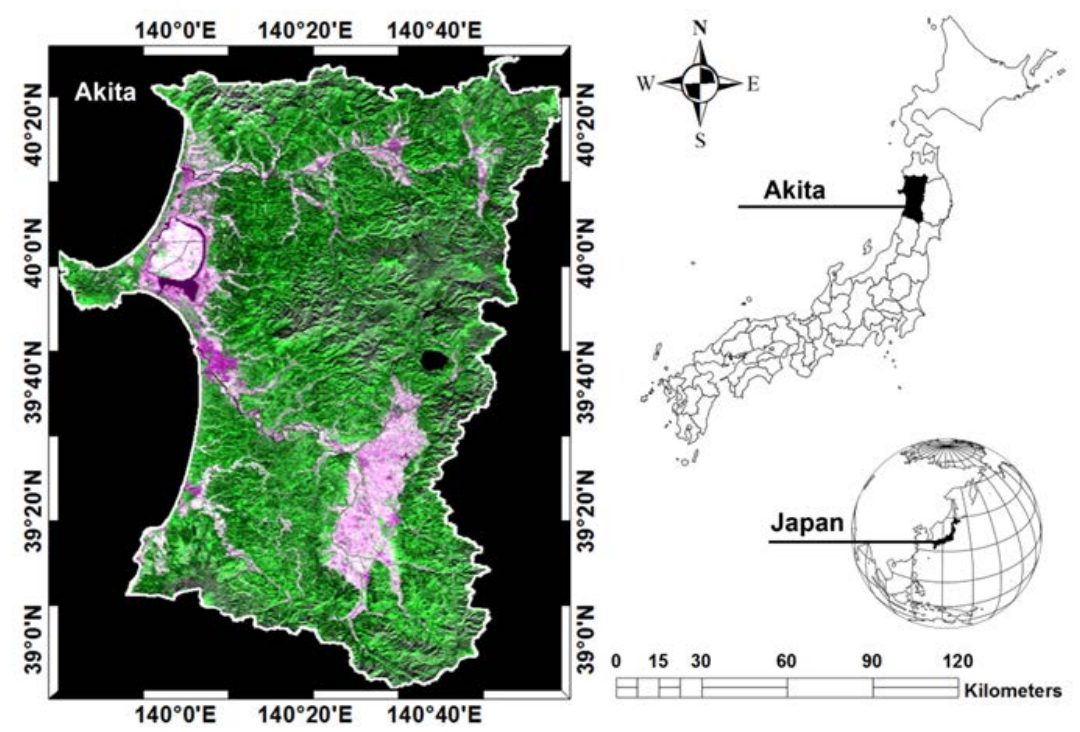

Figure 1. The MODIS image in Akita prefecture of Japan taken on the October 8, 2012, which is the $250 \mathrm{~m}$ true color image synthesized from RGB 121 . The green part in the left image represents vegetation and other parts represent no vegetation. The right figure represents the location of Akita prefecture in Japan.

Akita prefecture is selected as the study area in this work for the following three reasons:

First, Akita is the typical climate of the Sea of Japan, with abundant snowfall in winter. Because of the influence of the sea wind, coastal areas have relatively few snow cover on the ground and there are plenty of snow cover on the ground in inland area, which can help to clearly judge the SCD method is effective or not.

Second, Akita prefecture is a village with large area and high density of forests. Tree species are relatively simple, mainly are coniferous and deciduous forests. Hence, whether the SCD method can detect the snow pixels hidden by forest or not can be clearly evaluated.

Third, due to there are many mountains and large terrain variations in Akita, we can clearly evaluate whether the SCD method can detect the snow pixels in the large terrain variation regions or not.

\subsection{MODIS Data}

The Moderate Resolution Imaging Spectroradiometer (MODIS) is a key instrument aboard the Terra satellite, which was launched on December 18, 1999. It collects data from 36 spectral bands at three spatial resolutions ( $250 \mathrm{~m}, 500 \mathrm{~m}$ and $1000 \mathrm{~m}$ ), and the wavelength for viewing the entire earth's surface ranges from $0.4 \mu \mathrm{m}$ to $14.4 \mu \mathrm{m}$. Terra as a sun synchronous polar orbiting satellite, its orbit around the earth is timed so that it passes across the equator from north to south in the morning, and can provide global coverage data every 1 to 2 days.

MODIS has 44 standard data products. They can enable us to improve our understanding of global dynamics and processes occurring in the earth, oceans, and atmosphere, playing a major role in the development of predictive models of global climate change, the status of the melting ice and snow and agricultural production. MODIS products are organized into different processing levels. Level 0 product is raw digital number images. Level 1 product includes uncalibrated and calibrated radiance values. Level 2, 3 and 4 products have more processing and are derived from lower level products [14].

MODIS data are selected in this study because of its high spatial, time and spectral resolution. It can not only monitor the sudden changing natural disasters in real-time, but also improve the observation ability for the earth complex systems and the identification ability for the earth's surface. In addition, the satellite images covering the entire Akita prefecture can be obtained almost every day.

\subsection{DEM Data}

Digital Elevation Model (DEM) is a digital geographic dataset of elevations in xyz coordinates. It is typically used in extracting terrain parameters for geomorphology, creating relief maps, analyzing terrain in geomorpho- 
logical, and in terrain correction [15].

In this work, American National Aeronautics and Space Administration (NASA) Shuttle Radar Topographic Mission (SRTM) DEM data with $90 \mathrm{~m}$ resolution are used to conduct the topographic correction across the study area. SRTM $90 \mathrm{~m}$ DEM is available for over $80 \%$ of the entire globe, including Japan, and its vertical error is reported to be less than $16 \mathrm{~m}$. So far, the SRTM $90 \mathrm{~m}$ DEM data have 4 versions (http://srtm.csi.cgiar.org), and in this study, the latest version 4 is selected as the highest quality SRTM dataset. Currently, DEM data are distributed by the United States Geological Survey (USGS) free of charge and can be obtained from the National Map Seamless Data Distribution System website (http://srtm.csi.cgiar.org).

\subsection{AMeDAS}

Automated Meteorological Data Acquisition System (AMeDAS) is a high-resolution surface observation network developed by the Japan Meteorological Agency (JMA). It is used for gathering regional weather data and verifying forecast performance. The AMeDAS snow depth data operated on November 1, 1974, and currently comprises 1300 stations throughout Japan. It is an automated measuring dataset, comprising a supersonic gauge measurement for snow depth. Hourly observation data $(\mathrm{cm})$ of snow depth over 24 hour periods can be recorded (http://www.jma.go.jp/jma/kishou/know/amedas/kaisetsu.html). Akita Local Meteorological Observatory also operated AMeDAS data in 1974, and to date has deployed 13 observation stations across the entire prefecture (http://www.jma-net.go.jp/akita/yoho.htm).

In this work, AMeDAS snow depth data from the 6 observation stations which can observe snow and provide the snow depth record data are obtained from the JMA website

(http://www.data.jma.go.jp/obd/stats/etrn/index.php). They are selected for conducting practical objective judgment and comparing with the SCD results from the proposed method.

\subsection{RSIS}

Road Snow Information System (RSIS) is also an automated measured observation network developed by the Akita Construction Department Road Division used for gathering snow depth and snowfall data on the road surface and outside of the road across the entire Akita prefecture. In this system, snowfall sensor, frozen road detection sensor and workstation are combined online, and then snowfall and freezing information are collected in real-time. It is intended to give information for timely snow removal, anti-freezing agent spraying, and optimization and faster on the road surface management in winter. RSIS was operated in 1996, and currently comprises 31 observation stations throughout the whole Akita prefecture (http://www.pref.akita.lg.jp/www/genre/0000000000000/1000000001048/index.html). It can record hourly observation data $(\mathrm{cm})$ of snow depth over 24 hour periods.

In this work, in order to evaluate the effectivity of the proposed method for the SCD results, RSIS snow depth data from the 25 observation stations which can provide the long time and continuous observation record data obtained from the Akita Construction Department Road Division are selected.

The snow depth records of 31 observation stations have been selected, which are Furutoobe, Hakka, Nakataki, Towadaminami, Toroko, Yonaizawa, Tokko, Noshiro (RSIS), Hachimori, Showa, Takahi, Funagawa, Tateai, Kmagadai, Jinego, Omagari, Kariwano, Ota, Nangai, Tozawa, Yokote (RSIS), Jumonji, Akinomiya, Yuzawa (RSIS), Minase, Kazuno, Akita, Takanosu, Kakunodate, Yokote (AMeDAS) and Yuzawa (AMeDAS). Figure 2(a) shows the spatial geographic distributions of these 31 snow depth observation stations in the Akita prefecture. Figure 2(b) lists the detailed information of 31 snow depth observation stations, including the station ID numbers, data type, station name, station name abbreviation, latitude, longitude and start observation years.

\section{Methodology}

In this study, the MODIS/Terra Calibrated Radiances 5-Min L1B Swath 500 m (MOD02HKM) product data, the MODIS geolocation product (MOD03-Geolocation) data, the MODIS/Terra Snow Cover 5-Min L2 Swath 500 m (MOD10_L2) product data, the administrative regional boundary ShapeFile data of Akita prefecture, visibility and average altitude data of Akita prefecture, the RSIS snow depth data, the AMeDAS snow depth data, the SRTM 90 m DEM data, geographic coordinates data of 31 observation stations are applied for the SCD in Akita prefecture. 


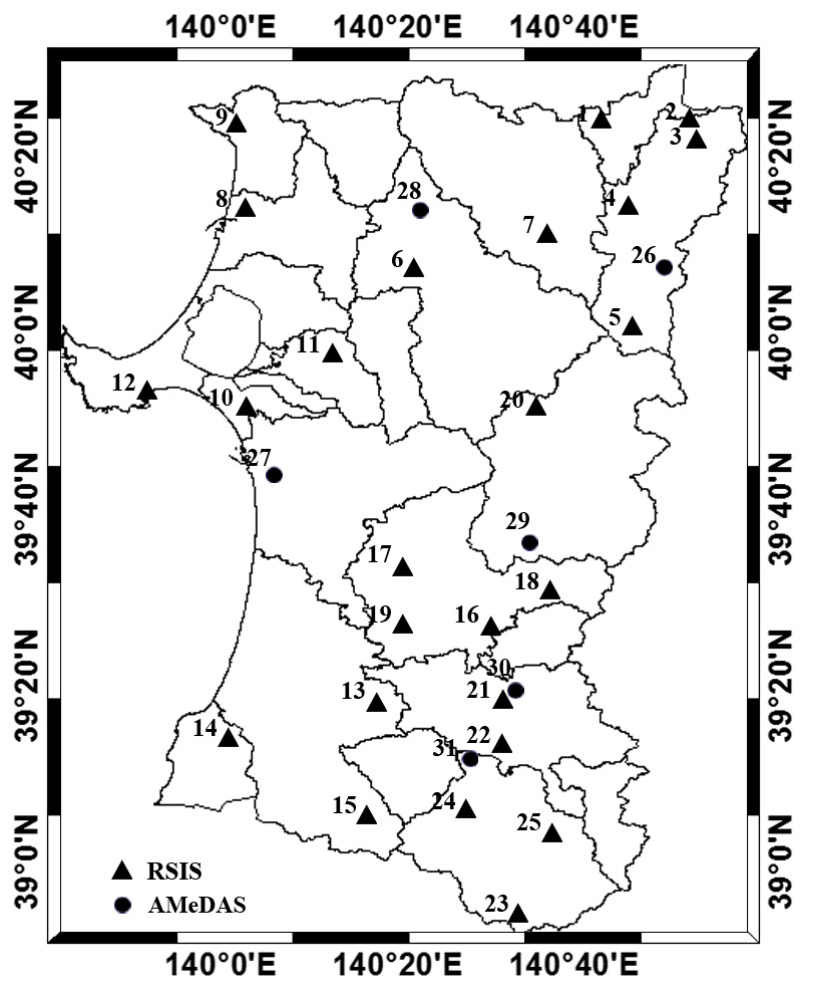

(a)

\begin{tabular}{|c|c|c|c|c|c|c|}
\hline $\begin{array}{l}\text { Station } \\
\text { ID } \\
\text { Numbers }\end{array}$ & $\begin{array}{l}\text { Data } \\
\text { Type }\end{array}$ & $\begin{array}{l}\text { Station } \\
\text { Name }\end{array}$ & $\begin{array}{l}\text { Station } \\
\text { Name } \\
\text { Abbreviation }\end{array}$ & $\begin{array}{l}\text { Latitude } \\
\left({ }^{\circ} \text { North) }\right.\end{array}$ & $\begin{array}{l}\text { Longitude } \\
\text { (' East) }\end{array}$ & $\begin{array}{l}\text { Start } \\
\text { Year }\end{array}$ \\
\hline 1 & RSIS & Furutoobe & Fur. & 40.31 & 140.75 & 1996 \\
\hline 2 & RSIS & Hakka & Hak. & 40.40 & 140.92 & 1996 \\
\hline 3 & RSIS & Nakataki & Nak. & 40.37 & 140.89 & 1996 \\
\hline 4 & RSIS & Towadaminami & Tow. & 40.26 & 140.76 & 1996 \\
\hline 5 & RSIS & Toroko & Tor. & 40.13 & 140.79 & 1996 \\
\hline 6 & RSIS & Yonaizawa & Yon. & 40.04 & 140.55 & 1996 \\
\hline 7 & RSIS & Tokko & Tok. & 40.19 & 140.60 & 1996 \\
\hline 8 & RSIS & Noshiro & Nos. & 40.23 & 140.02 & 1997 \\
\hline 9 & RSIS & Hachimori & Hac. & 40.37 & 140.02 & 1997 \\
\hline 10 & RSIS & Showa & Sho. & 39.86 & 140.05 & 1997 \\
\hline 11 & RSIS & Takahi & Tak. & 39.96 & 140.21 & 1997 \\
\hline 12 & RSIS & Funagawa & Fun. & 39.89 & 139.84 & 1997 \\
\hline 13 & RSIS & Tateai & Tat. & 39.31 & 140.30 & 1996 \\
\hline 14 & RSIS & Kamagadai & Kam. & 39.24 & 140.03 & 1996 \\
\hline 15 & RSIS & Jinego & Jin. & 39.10 & 140.28 & 1996 \\
\hline 16 & RSIS & Omagari & Oma. & 39.45 & 140.48 & 1997 \\
\hline 17 & RSIS & Kariwano & Kar. & 39.54 & 140.37 & 1997 \\
\hline 18 & RSIS & Ota & Ota & 39.45 & 140.55 & 1997 \\
\hline 19 & RSIS & Nangai & Nan. & 39.48 & 140.47 & 1997 \\
\hline 20 & RSIS & Tozawa & Toz. & 39.86 & 140.57 & 1997 \\
\hline 21 & RSIS & Yokote & Yok. & 39.30 & 140.53 & 1997 \\
\hline 22 & RSIS & Jumonji & Jum. & 39.22 & 140.53 & 1997 \\
\hline 23 & RSIS & Akinomiya & Aki. & 38.94 & 140.55 & 1996 \\
\hline 24 & RSIS & Yuzawa & Yuz. & 39.16 & 140.49 & 1996 \\
\hline 25 & RSIS & Minase & Min. & 39.06 & 140.63 & 1996 \\
\hline 26 & AMeDAS & Kazuno & Kaz. & 40.22 & 140.79 & 1977 \\
\hline 27 & AMeDAS & Akita & Aki. & 39.72 & 140.10 & 1998 \\
\hline 28 & AMeDAS & Takanosu & Tak. & 40.23 & 140.37 & 1977 \\
\hline 29 & AMeDAS & Kakunodate & Kak. & 39.60 & 140.56 & 1977 \\
\hline 30 & AMeDAS & Yokote & Yok. & 39.32 & 140.56 & 1977 \\
\hline 31 & AMeDAS & Yuzawa & Yuz. & 39.19 & 140.46 & 1985 \\
\hline
\end{tabular}

(b)

Figure 2. (a) Distribution of the 31 snow depth observation sensors across the entire Akita prefecture ( $\boldsymbol{\Delta}$ : Location of snow depth observation sensors from RSIS which have 25 observation sensors in all; $\mathbf{0}$ : Location of snow depth observation sensors from AMeDAS which have 6 observation sensors in all); (b) The detailed information of 31 observation stations across the entire prefecture.

MOD02HKM belongs to the MODIS Level 1B dataset, while MOD10_L2 belongs to the MODIS Level 2 dataset. MODIS Level 1B data are obtained from the Level 1 and Atmosphere Archive and Distribution System (LAADS) website (http://ladsweb.nascom.nasa.gov). MODIS Level 2 data are obtained from the Next Generation Metadata and Service Discovery Tool "Reverb" website of Earth Observing System Data and Information System (EOSDIS) of NASA (https://earthdata.nasa.gov).

In addition, the copyright of the Akita prefecture administrative regional boundary ShapeFile data belongs to the Esri Japan Corporation, and the data can be obtained from ShapeFile library website

(http://www.okada.jp.org/RWiki/?ShapeFile\%A5\%E9\%A5\%A4\%A5\%D6\%A5\%E9\%A5\%EA).

Figure 3 shows the flowchart of the SCD method proposed in this study. The pre-processing including geographic correction, study area clipping, atmospheric correction and topographic correction are conducted before the SCD. Then the reflectance images of band 1 (red, $0.620-0.670 \mu \mathrm{m}$ ) and band 3 (blue, $0.459-0.479 \mu \mathrm{m}$ ) are obtained and used to detect the snow cover pixels by setting their threshold values. Finally, the SCD results of the study area are obtained. Here, it is necessary to clear that the whole operation process of this study is conducted at Interface Description Language (IDL) language environment platform.

\subsection{Geographic Correction}

In order to remove internal and external distortions and precisely identify the location of each pixel on the earth, the MODIS Swath Reprojection Tool (MRT Swath) is applied for geographic correction of image. The MRT Swath is developed by the Land Processes Distributed Active Archive Center (LP DAAC) for MODIS Level 1B products and Level 2 land product data, and can be obtained from the website of LP DAAC in USGS

(https://lpdaac.usgs.gov/tools/MODIS_reprojection_tool_swath). In this step, MOD03-Geolocation data are also used due to all projections requiring the corresponding additional inputs. During this process, format type of 


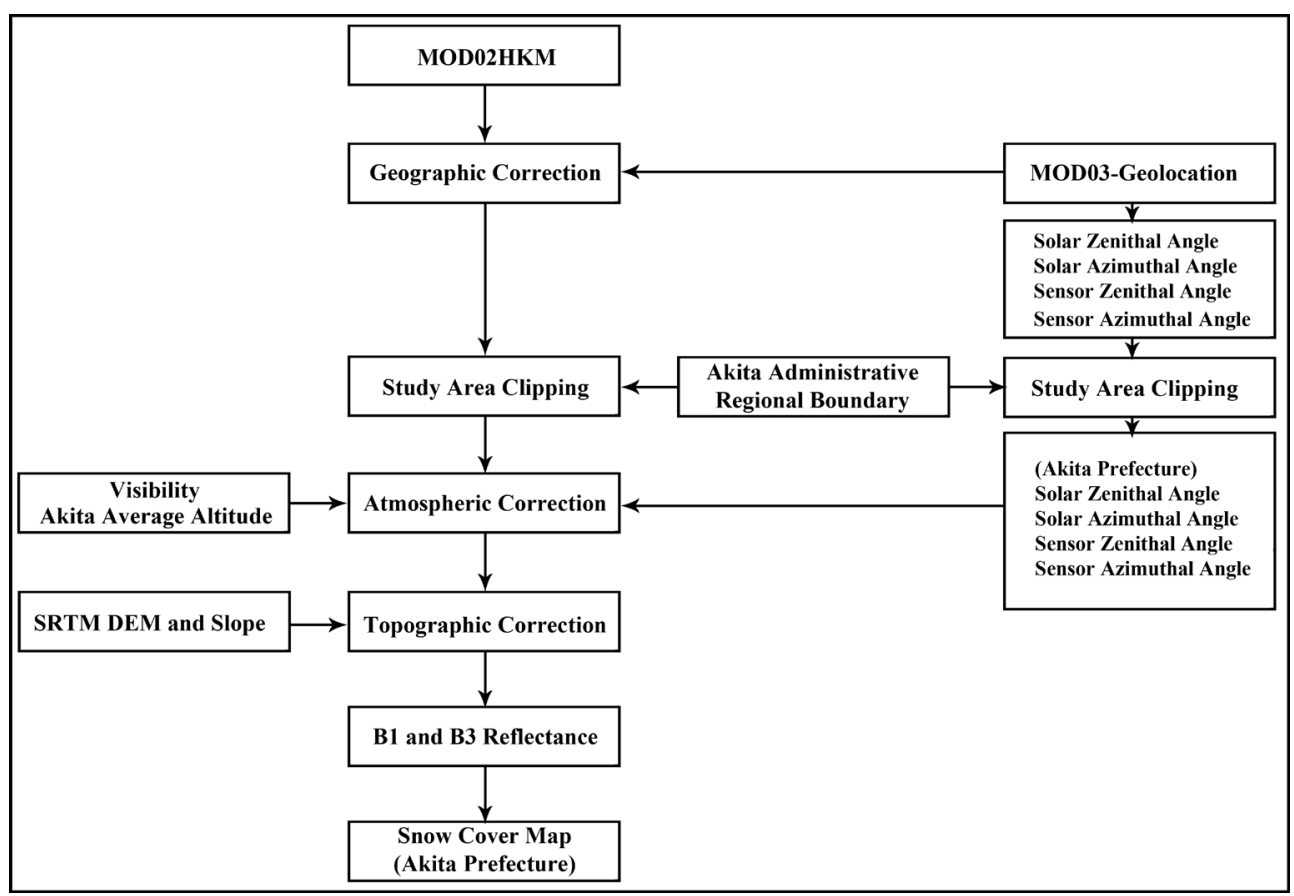

Figure 3. The flowchart of the SCD method proposed in this study.

output file is GeoTIFF, the resampling type is nearest neighbor, the projection type is geographic, and the output pixel size is 0.0045 degrees at $500 \mathrm{~m}$ spatial resolution [16].

\subsection{Study Area Clipping}

To remove those areas that do not belong to the study area and decrease the amount of calculations, the administrative regional boundary ShapeFile data of Akita prefecture are used to clip the acquired image after accomplished geographic correction. The clipped image is directly used for atmospheric correction in the next step.

\subsection{Atmospheric Correction}

The study area image with precise latitude and longitude is obtained after the above processing. However, this image still continues the properties of MODIS Level 1B product data. That is, the MODIS Level 1B product has been calibrated, but its reflectance only represents the apparent reflectance at the top of atmosphere, and not the real ground surface reflectance. In order to return real ground surface reflectance of the target area and eliminate the atmosphere scattering and absorbance impacts from water vapor, carbon dioxide, ash and smoke dust in the atmosphere which are the primary factors for generating error in the SCD, the geographically corrected and study area clipped image should be atmospheric corrected.

The Second Simulation of a Satellite Signal in the Solar Spectrum (6S) code model is applied for atmospheric correction in this study. It is a basic Radiative Transfer (RT) code used for the calculation of Look Up Tables (LUTs) in the MODIS atmospheric correction algorithm. It can accurately simulate and calculate the parameters of the study target, background, topography, weather, spectrum and sensor conditions, thus can obtain the relationship between the apparent reflectance from atmosphere and the real surface reflectance from ground [17], [18].

This atmospheric correction can be calculated online, and obtained from the website of the MODIS Land Surface Reflectance Science Computing Facility, 6S Vector Code (http://6s.ltdri.org).

Table 1 lists the detailed parameters of the 6S code atmospheric correction with MODIS images from the Terra satellite acquired on April 2, 2014, 10:00 AM (Japan Standard Time (JST)).

After the all above processing, the equations of real ground surface reflectance and the apparent reflectance from the top of the atmosphere can be obtained with three atmospheric correction coefficients $x_{a}, x_{b}$, and $x_{c}$ as shown in Equations (1) and (2). 
Table 1. The parameters of the 6S code atmospheric correction.

\begin{tabular}{|c|c|c|}
\hline \multicolumn{2}{|c|}{ Parameter Items } & \multirow{2}{*}{$\begin{array}{c}\text { Parameter Values } \\
4\end{array}$} \\
\hline \multirow{6}{*}{$\begin{array}{l}\text { Geometrical } \\
\text { Conditions } \\
\text { (User's) }\end{array}$} & Month & \\
\hline & Day & 2 \\
\hline & Solar Zenithal Angle & 42.513333 \\
\hline & Solar Azimuthal Angle & 141.155259 \\
\hline & Sensor Zenithal Angle & 50.785289 \\
\hline & Sensor Azimuthal Angle & 95.193096 \\
\hline \multirow{3}{*}{$\begin{array}{l}\text { Atmospherical } \\
\text { Model }\end{array}$} & Atmospheric Profile & Midlatitude Winter \\
\hline & Aerosol Model & Maritime Model \\
\hline & Visibility (km) & 20 \\
\hline \multirow{2}{*}{$\begin{array}{c}\text { Target \& } \\
\text { Sensor Altitude }\end{array}$} & Target Altitude (km) & -0.097 \\
\hline & Sensor Altitude & $(-1000)$ Satellite Level \\
\hline \multirow{2}{*}{ Spectral Conditions } & \multirow{2}{*}{ Spectral Conditions } & MODIS Band1 \\
\hline & & MODIS Band3 \\
\hline \multirow{3}{*}{ Ground Reflectance } & Ground Reflectance Type & Homogeneous Surface \\
\hline & Directional Effects & Directional Effects \\
\hline & Specify Surface Reflectance & MODIS operational BRDF \\
\hline Signal & Atmospheric Correction Mode & Atmospheric Correction with BRDF \\
\hline \multicolumn{3}{|c|}{$y=x_{a} \times($ measured radiance $)-x_{b}$} \\
\hline & $\mathrm{acr}=\frac{y}{\left(1+x_{c} \times y\right)}$ & \\
\hline
\end{tabular}

where the measured radiance is the apparent reflectance from the top of the atmosphere and acr is the real ground surface reflectance.

\subsection{Topographic Correction}

The study area Akita prefecture is a mountainous region with rugged terrain. Reflected brightness changes caused by irregular topography can lead to the inconsistency phenomenon of the reflectance from similar or identical ground surface features, which results in the accuracy reduction in process of the SCD. In order to reduce the impact of the inconsistency phenomenon and improve the accuracy of the SCD, topographic correction is conducted for the atmospheric corrected image in the study region.

Before the topographic correction, the SRTM 90 m DEM data are conducted to be resampled by the geographic projection and cut with the administrative regional boundary ShapeFile data of Akita prefecture at 500 $\mathrm{m}$ resolution. Then, image registration in pixel level is conducted for matching the study area image. Finished the all above steps, the obtained SRTM 90 m DEM data are applied for topographic correction.

In this work, topographic correction method developed by Dubayah [19] and a shadowing function algorithm developed by Hapke [20] are adopted for the study region [21].

\subsection{Spectral Analysis}

The MODIS imagery of the real ground surface reflectance in the study region can be obtained after completion of the above pre-processing operations.

In order to analyze the spectrum distribution of the ground surface substances in bands 1 and 3 within the 
study area, the spectrums of the ground surface substances in accordance with clear day conditions of Akita prefecture are searched and produced from the relevant spectral libraries. Figure 4 shows the ideal standard reflectance spectrums of the various representative ground surface substances in Akita prefecture, such as snow, soil, deciduous, conifer, grass and water.

From Figure 4, it can be seen that the reflectance spectrums of different substances can be clearly distinguished in the visible red band 1, blue band 3 and green band $4(0.545-0.565 \mu \mathrm{m})$. In these three bands, the reflectance of snow is the highest, followed in order by soil and other vegetation (deciduous, conifer and grass). Vegetation has much lower reflectance because of the strong chlorophyll absorption among these three wavelengths. The reflectance of water is only $5 \%$, which is the smallest in all of the substances. Due to green vegetation shows a small reflectance peak in band 4, there may be some difficulties during the identification of mixed snow and green vegetation pixels. Therefore, the visible bands 1 and 3 are selected to detect and distinguish snow pixels from other ground surface substances in this work.

\subsection{The Snow Distribution of Study Area in Different Periods}

In order to investigate the snow cover distribution at different periods in the study area, we selected 5 types of typical snow cover distribution situations images from May 2012 to April 2014 on clear days as the training images and are shown in Figure 5.

Figure 5 shows the true color images composited by MODIS images of the Terra satellite at $500 \mathrm{~m}$ spatial resolution in different periods. The winter of Akita prefecture is from the late December to early February, so the whole study area is almost covered by snow as shown in Figure 5(a). The white area represents snow cover, its brightness increased with the snow cover becoming thicker. The deep green area represents the bared vegetation, because the snow cover on the branches are blown down by the strong sea wind, which lead to some of the forest is exposed. On the other hand, there is no snow cover over the Tazawa Lake and shows black colors because it keeps ice-free all the year round.

From Figure 5(b), it can be seen that some of snow cover began to melt in March, but there are still snow cover in most of the study area. In fact, all of snow cover distributed in the mountain and basin areas of inland but not in the coastal area. It is because that the snow cover in coastal area was blown to the inland by strong sea wind. Therefore, the bared soil in the coastal area shows the dark brown. In addition, there is also no snow cover on the Hachirougata Choseichi in the southeast of Oga Peninsula.

In May, the weather of the whole study area warms into spring, most of snow cover has been melted, and there is only snow cover on the top of mountains in inland as shown in Figure 5(c). The dark brown area is the bared land with the buds of green vegetation like grass, and the dark green area is the forest. Meantime, the Tazawa Lake on the satellite images begins to show the blue color due to the strong light of sun.

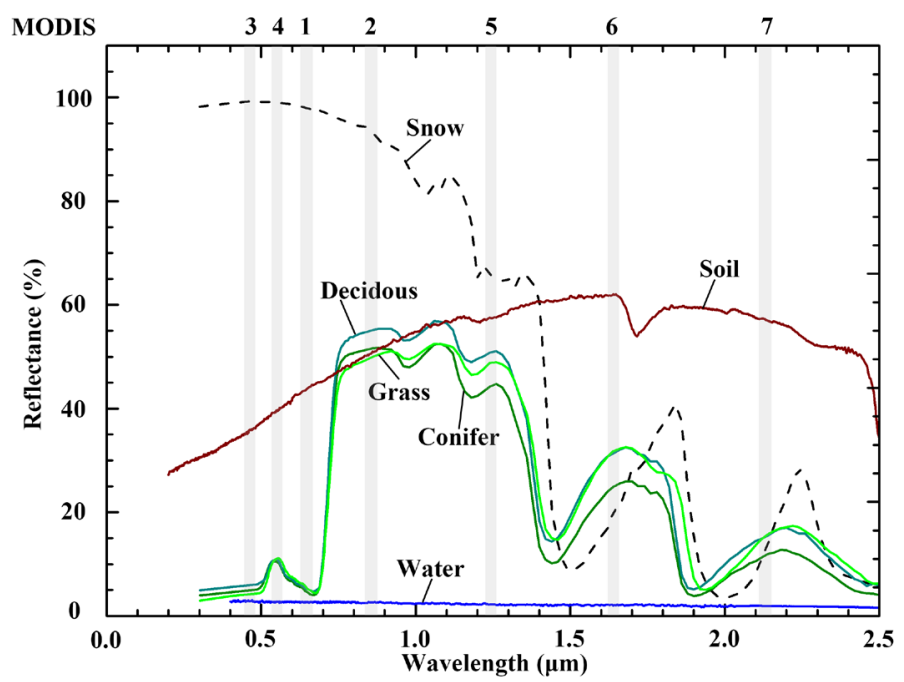

Figure 4. Spectral reflectance curves of snow, soil, vegetation (deciduous, conifer and grass) and water. 

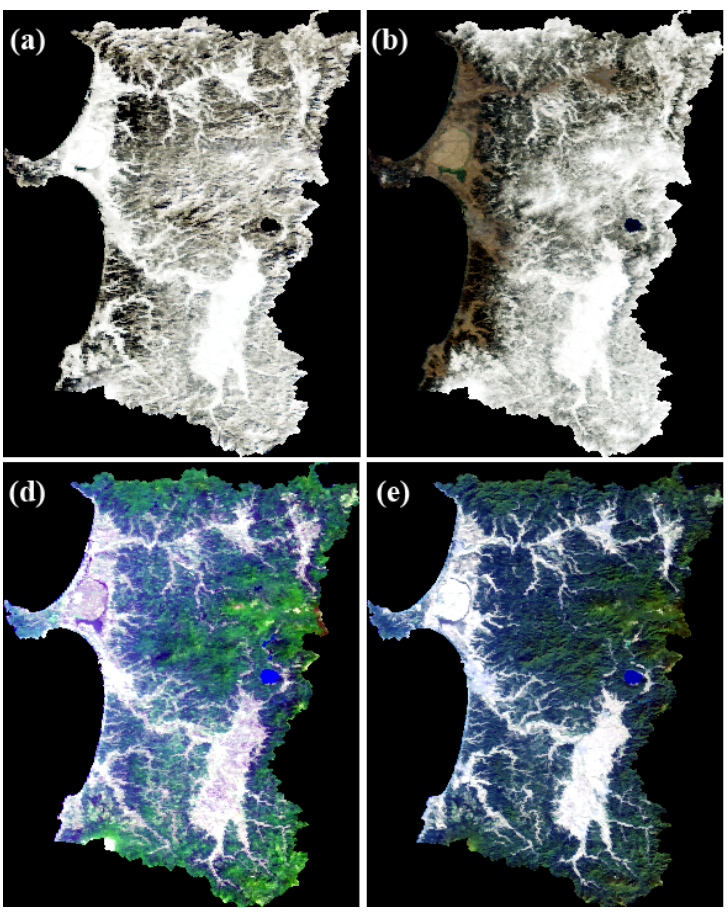

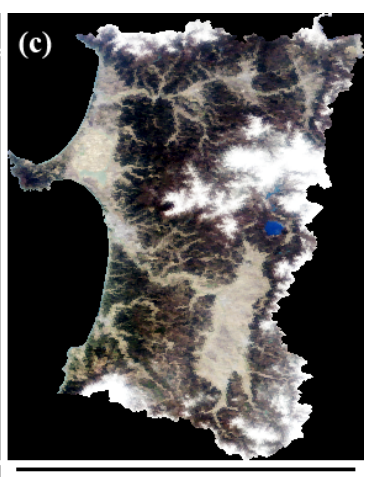

(a)

All snow, not melted December 29, 2012 10:20:00 (JST) (b)

Mostly snow, Less melted March 7, 2014 10:35:00 (JST) (c)

Less snow, Mostly melted May 9, 2013 10:50:00 (JST) (d)

Only Mt. Chokaizan snow June 27, 2012 10:25:00 (JST)

(e)

October 8, 2012 10:30:00 (JST)

Figure 5. The true color images composited by MODIS images of Terra satellite at 500 m spatial resolution in different periods (a) 10:20:00 AM on December 29, 2012, snow was not melted; (b) 10:35:00 AM on March 7, 2014, snow was melted a little; (c) 10:50:00 AM on May 9, 2013, mostly snow was melted; (d) 10:25:00 AM on June 27, 2012, snow covered only on Mt. Chokaizan; (e) 10:30:00 AM on October 8, 2012, no snow.

With the study area entering into the late June, almost all of snow cover has been melted due to the continuous high temperature of summer. There is only still a little snow cover on the peak of Mt. Chokaizan which locates in the southwest corner of the Akita prefecture as shown in Figure 5(d). It is because that the altitude of Mt. Chokaizan is $2236 \mathrm{~m}$ and the temperature on the top of the mountain is much lower. Other places across the whole study area have a large area of the vegetation and the bared land has become the agricultural land. They show the bright green color from the satellite images.

In October, the study area enters into the alternate season of summer and autumn. Due to the continuous high temperature of summer in July, August and September, there is not any snow cover even on the Mt. Chokaizan as shown in Figure 5(e). At this time, the forest is still lush and shows dark green. And due to the harvest of the crops, the agricultural land turns into bared land again. But the brightness on the satellite images is higher than before because only weeds are left.

\subsection{2-Dimensional Scatter Plot Analysis}

Based on the above analysis, we conclude that when the reflectance value of one pixel is greater than the soil, this pixel will be judged as the snow pixel. From Figures 6(a)-(e), the largest reflectance values of soil pixels in visible bands 1 and 3 are 0.458 and 0.60 , respectively. Therefore, in this work, the threshold values are determined as greater than 0.458 in band 1 and greater than 0.60 in band 3 .

A 2-dimensional scatter plot density distribution can further illustrate the pixel distributions of various substances in the study area. Figure 6 shows the 2-dimensional scatter plot density distributions of the above 5 types of training images in visible red band 1 and blue band 3. Figures 6(a)-(e) are the 2-dimensional scatter plot density distributions across the whole study area which represent that there are all snow cover and not melted situation, at 10:20:00 AM on the December 29, 2012, there are mostly snow cover and less melted situation, at 10:35:00 AM on the March 7, 2014, there are less snow cover and mostly melted situation, at 10:50:00 AM on the May 9, 2013, there are only snow cover on the top of the Mt. Chokaizan, at 10:25:00 AM on the June 

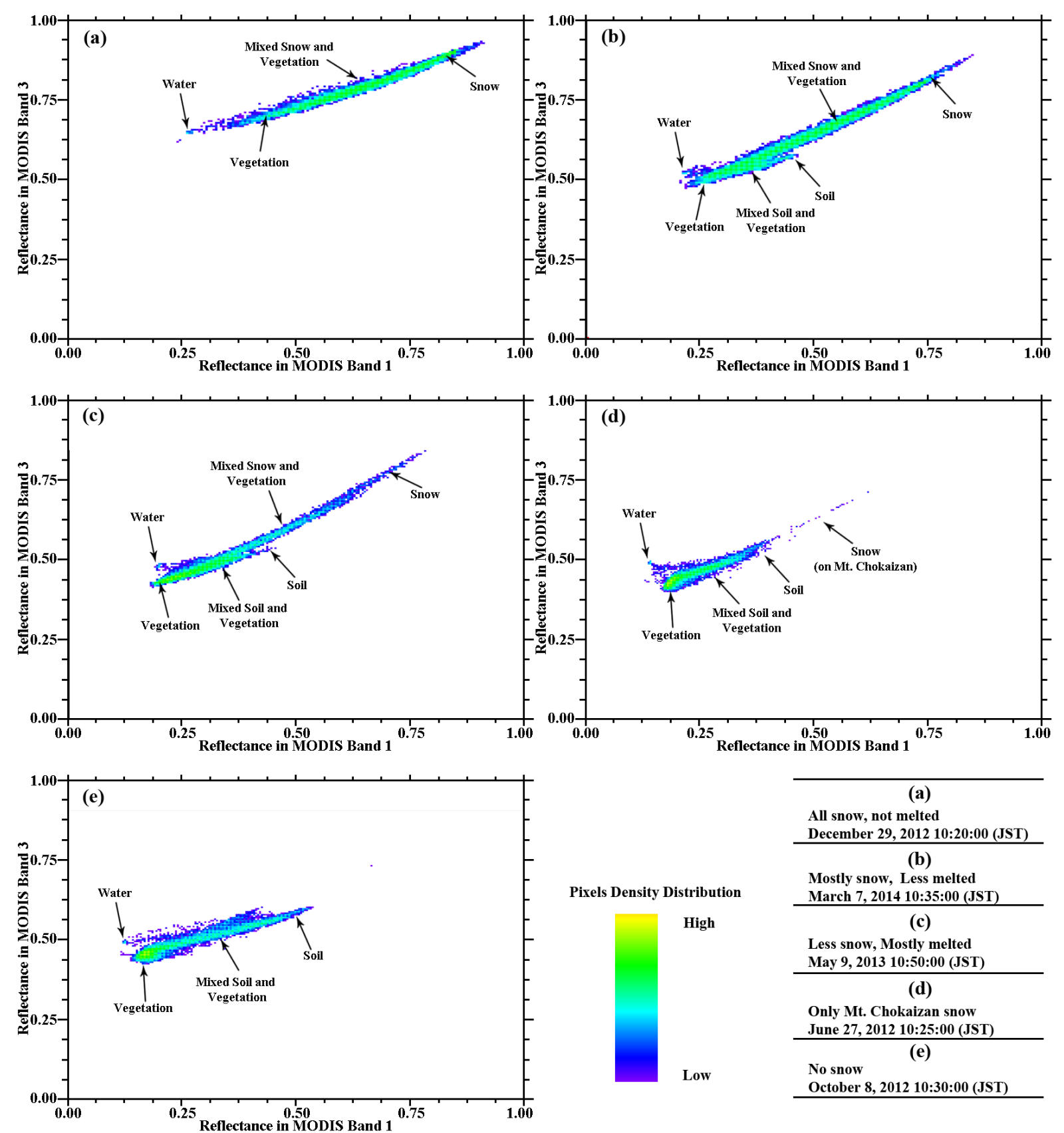

Figure 6. The 2-dimensional scatter plot density distributions of 5 types of images in bands 1 and 3.

27, 2012, and there are no snow cover situation, at 10:30:00 AM on the October 8, 2012, respectively. The density distribution location of each substance in the 2-dimensional scatter plot is marked in these 5 types of different figures.

From Figure 6, it is obvious that snow pixels decreased from (a) to (d) until it disappeared in (e). The reflectance values of images from (a) to (e) also decreased along with the snow pixels decreasing in the MODIS visible red band 1 and blue band 3. Combining with the composited true color images in Figure 5, from Figure 6(a), it can be seen that there are only 3 types substances which are snow, vegetation (conifer and deciduous forest) and water. Due to all of the study area are almost covered by snow in winter, the pixels are mainly snow and the distributions of the pixels mainly locate at the top right part of the whole 2-dimensional scatter plot density distribution figure. With the weather warming, the snow began to melt and some of bared lands in the coastal re- 
gion gradually appeared. The whole 2-dimensional scatter plot density distribution figure shows some soil pixels which located in the lower part of the snow and vegetation mixed pixels in the visible blue band 3 from Figure 6(b) and Figure 6(c). In Figure 6(d), due to there is only still a little snow cover on the peak of Mt. Chokaizan, the snow pixels still exist at the top right part of the whole 2-dimensional scatter plot density distribution figure. And due to the bared land has become the agricultural land, the soil pixels in the 2-dimensional scatter plot also disappeared and became into the vegetation pixels again. In Figure 6(e), there is not any snow cover across the whole study area, all of substances pixels become relative clearness. There are only three kinds of substances pixels which are soil, vegetation and water pixels. In addition, the reflectance of soil pixels became the biggest in the absence of snow pixels.

\section{Result and Discussion}

Figure 7 shows a composited RGB (143) true color image (a) and the SCD results of proposed method (b) and MOD10_L2 (c) on April 2, 2014. Here, (a) as the reference of visual judgment is applied to be objectively compared with the SCD results of (b) and (c).

From Figure 7(a), it can be seen that there is snow cover in the forest and basin areas of the inland, but no snow cover in the coastal area including Oga Peninsula and the Tazawa Lake. There are some black flecks which represent that the snow pixels are not detected out near the Yokote (RSIS), Jumonji, Yuzawa (RSIS), Yokote (AMeDAS) and Yuzawa (AMeDAS) observation stations in Figure 7(c), while the proposed method has detected the snow pixels of these areas out in Figure 7(b), consistent with (a). Furthermore, there are also some black cracks near the Jinego observation station in Figure 7(c), because of the snow pixels are not detected out. On the contrary, the proposed method has detected the snow pixels of these regions in Figure 7(b). It demonstrates that snow cover pixels of the study area can be detected out more accurately than MOD10_L2 according to the visual judgment.

Table 2 shows the comparison results of the in-situ data, the proposed method and MOD10_L2 product for the SCD in the study area on April 2, 2014. In this table, I is the records of the RSIS and AMeDAS snow depth, II is the results from proposed method, III is the results from MOD10_L2 products. Meanwhile, "1" represents snow covered and " 0 " represents snow free.

From Table 2, it can be seen that there are snow cover pixels in the observation stations of Toroko, Tateai, Kamagadai, Jinego, Kariwano, Yokote (RSIS), Jumonji, Akinomiya, Yuzawa (RSIS) and Kakunodate with the proposed method. But there are no snow cover pixels on these observation stations from the MOD10_L2 product. In Furutoobe, the snow cover depth is $65 \mathrm{~cm}$ from the RSIS data of in-situ data, but there are not any snow cover pixels to be detected out by both the proposed method and MOD10_L2 products. In Yonaizawa, there is no snow over from the RSIS data of in-situ data, oppositely both the proposed method and MOD10_L2 product have detected snow cover pixels out wrongly.

In order to further compare and evaluate the accuracies of the SCD results with the proposed method and MOD10_L2, the following validation method as Table 3 shown is adopted.

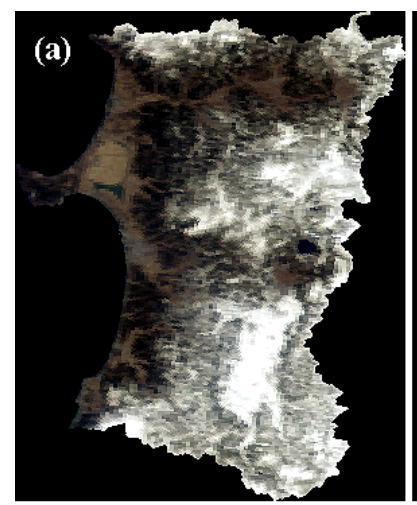

Composited RGB(143) image

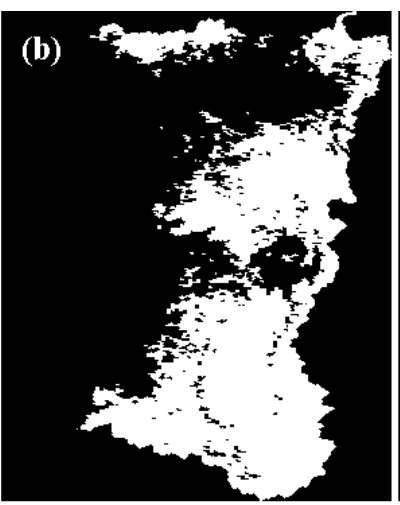

Proposed Method

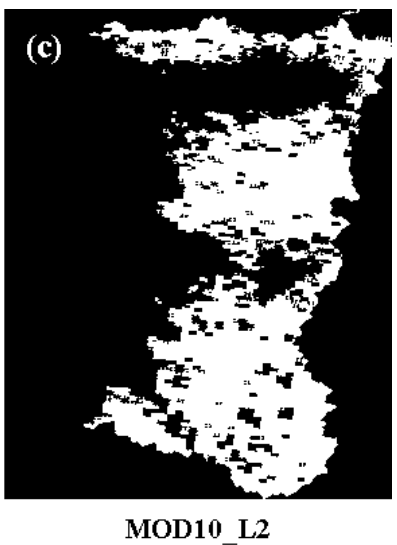

MOD10 L2

Figure 7 . The reference image composited by RGB $(1,4$, and 3$)$ and the final results of the SCD with Proposed Method (b) and MOD10_L2 (c). 
Table 2. The SCD results from in-situ Data (I), Proposed Method (II), MOD10_L2 (III) on April 2, 2014.

\begin{tabular}{cccccccccc}
\hline Station ID & Station Name & I & II & III & Station ID & Station Name & I & II & III \\
\hline 1 & Furutoobe & 65 & 0 & 0 & 17 & Kariwano & 7 & 1 & 0 \\
2 & Hakka & 207 & 1 & 1 & 18 & Ota & 12 & 1 & 1 \\
3 & Nakataki & 125 & 1 & 1 & 19 & Nangai & 56 & 1 & 1 \\
4 & Towadaminami & 0 & 0 & 0 & 20 & Tozawa & 166 & 1 & 1 \\
5 & Toroko & 195 & 1 & 0 & 21 & Yokote & 62 & 1 & 0 \\
6 & Yonaizawa & 0 & 1 & 1 & 22 & Jumonji & 61 & 1 & 0 \\
7 & Tokko & 0 & 0 & 0 & 23 & Akinomiya & 105 & 1 & 0 \\
8 & Noshiro & 0 & 0 & 0 & 24 & Yuzawa & 45 & 1 & 0 \\
9 & Hachimori & 0 & 0 & 0 & 25 & Minase & 156 & 1 & 1 \\
10 & Showa & 0 & 0 & 0 & 26 & Kazuno & 0 & 0 & 0 \\
11 & Takahi & 0 & 0 & 0 & 27 & Akita & 0 & 0 & 0 \\
12 & Funagawa & 0 & 0 & 0 & 28 & Takanosu & 0 & 0 & 0 \\
13 & Tateai & 56 & 1 & 0 & 29 & Kakunodate & 10 & 1 & 0 \\
14 & Kamagadai & 42 & 1 & 0 & 30 & Yokote & 47 & 1 & 1 \\
15 & Jinego & 116 & 1 & 0 & 31 & Yuzawa & 31 & 1 & 1 \\
16 & Omagari & 38 & 1 & 1 & & & & & 0 \\
\hline
\end{tabular}

I: Records of Snow Depth (cm) from in-situ Data; II: Results from Proposed Method; III: Results from MOD10_L2. “1”: Snow covered; "0”: Snow Free.

Table 3. The validation method for the SCD results.

\begin{tabular}{ccc}
\hline Date & \multicolumn{2}{c}{ In-Situ Observation Station } \\
\hline Proposed Method/MOD10_L2 & Snow & Snow-Free \\
Snow & $a$ & $b$ \\
Snow-Free & $c$ & $d$ \\
\hline
\end{tabular}

In which,

$a=$ where both the proposed method or MOD10_L2 and the in-situ observation stations detect snow;

$b=$ where the in-situ observation stations detect snow-free and the proposed method or MOD10_L2 detects snow;

$c=$ where the in-situ observation stations detect snow and the proposed method or MOD10_L2 detects snow-free;

$d=$ where both the proposed method or MOD10_L2 and the in-situ observation stations detect snow-free;

Overall accuracy, over-estimation error and under-estimation error are calculated according to the following equations applying the above parameters in Table 3.

$$
\begin{gathered}
\text { Overall accuracy }=\frac{a+d}{a+b+c+d} \\
\text { Over-estimation error }=\frac{b}{a+b+c+d} \\
\text { Under-estimation error }=\frac{c}{a+b+c+d}
\end{gathered}
$$


Based on the above validation method and the SCD results of Table 2, the overall accuracy, over-estimation error and under-estimation error of the proposed method are calculated, which are 93.55\%, 3.23\% and 3.23\% respectively, and overall accuracy, over-estimation error and under-estimation error of the MOD10_L2 product are $61.29 \%, 3.23 \%$ and $35.48 \%$ respectively. It suggests that the SCD accuracy of the proposed method is higher than MOD10_L2 products, and the under-estimation error of MOD10_L2 is greatly higher than the proposed method.

In order to further compare the SCD accuracies of these two methods, results of the overall accuracy, overestimation error and under-estimation error during the snowy season from May 2012 to April 2014 are calculated and listed as shown in Table 4. It is clear to see that the overall accuracy of the proposed method is all higher than the MOD10_L2 products. Over-estimation errors of the proposed method are lower than or equal to the MOD10_L2 products. Under-estimation errors of the proposed method are all much lower than the MOD10_L2 products. The average values of the overall accuracy, over-estimation error and under-estimation error are $88.94 \%, 0.92 \%$ and $10.14 \%$ respectively from the proposed method, and are $62.67 \%, 2.30 \%$ and $35.02 \%$ respectively from the MOD10_L2 product. Based on above results, we can know that the average overall accuracy of the proposed method is higher than MOD10_L2 product, improved by $26.27 \%$. These results fully prove that the effectivity of the proposed method for the SCD in this work.

In order to further verify and analyze the SCD results, in this work, all of the 31 observation stations across the whole study area are divided into three types according to the longitude and latitude locations of themselves, which are the forest regions (Furutoobe, Hakka, Nakataki, Yonaizawa, Takahi, Funagawa, Tateai, Kamagadai, Jinego, Tozawa, Akinomya, Minase and Kazuno), the plain regions (Towadaminami, Tokko, Toroko, Noshiro, Hachimori, Showa, Kariwano and Akita), and the basin regions (Omagari, Ota, Nangari, Yokote (RSIS), Jumonji, Yuzawa (RSIS), Takanosu, Kakunodate, Yokote (AMeDAS) and Yuzawa (AMeDAS)). Figure 8 shows the overall accuracy, over-estimation error and under-estimation error comparison results of these 31 observation stations based on the above three types of regions from the proposed method and the MOD10_L2 products during the snowy season from May 2012 to April 2014.

From Figure 8, it can be seen that there is almost no over-estimation errors for both the proposed method and the MOD10_L2 products in the plain, basin and forest regions except the Yonaizawa and Takahi in the forest areas. According to the principle of the proposed method, the reflectance of the substances is similar in visible bands 1 and 3. The reflectance of snow is much higher than other any substances, and the following is the soil. The maximum reflectance value of the soil is defined as the threshold value, which is higher than the reflectance of other any substances excluding snow. Therefore, the pixels of other substances are difficult to be detected out as snow pixels. For MOD10_L2 products, the reflectance of snow in visible green band 4 is higher than that in short infrared band 6, while other substances in these two bands are just opposite. Only the snow pixels can be detected out with normalized difference ratio of NDSI. So the pixels of other substances are also difficult to be detected out as snow pixels.

However, there are over-estimation errors in Yonaizawa for these two methods and in Takahi for only MOD10_L2 products. It may be due to the following three reasons: first, in the present study, the MODIS $500 \mathrm{~m}$

Table 4. The accuracy comparisons of the proposed method and the MOD10_L2 products.

\begin{tabular}{|c|c|c|c|c|c|c|c|c|}
\hline \multirow[b]{2}{*}{ Number } & \multicolumn{2}{|c|}{ Japan Standard Time } & \multicolumn{3}{|c|}{ Proposed Method } & \multicolumn{3}{|c|}{ MOD10_L2 } \\
\hline & Date & Time & $\begin{array}{c}\text { Overall } \\
\text { Accuracy (\%) }\end{array}$ & $\begin{array}{l}\text { Over-Estimation } \\
\text { Error (\%) }\end{array}$ & $\begin{array}{c}\text { Under-Estimation } \\
\text { Error (\%) }\end{array}$ & $\begin{array}{c}\text { Overall } \\
\text { Accuracy (\%) }\end{array}$ & $\begin{array}{l}\text { Over-Estimation } \\
\text { Error (\%) }\end{array}$ & $\begin{array}{c}\text { Under-Estimation } \\
\text { Error (\%) }\end{array}$ \\
\hline 1 & January 23, 2013 & $10: 10$ & 100.00 & 0.00 & 0.00 & 54.84 & 0.00 & 45.16 \\
\hline 2 & February 1, 2013 & $10: 05$ & 100.00 & 0.00 & 0.00 & 93.55 & 0.00 & 6.45 \\
\hline 3 & April 9, 2013 & $10: 35$ & 74.19 & 3.23 & 22.58 & 48.39 & 3.23 & 48.39 \\
\hline 4 & April 16, 2013 & $10: 40$ & 67.74 & 0.00 & 32.26 & 58.06 & 3.23 & 38.71 \\
\hline 5 & March 4, 2014 & $10: 30$ & 100.00 & 0.00 & 0.00 & 61.29 & 0.00 & 38.71 \\
\hline 6 & April 1, 2014 & $10: 55$ & 87.10 & 0.00 & 12.90 & 61.29 & 6.45 & 32.26 \\
\hline 7 & April 2, 2014 & $10: 00$ & 93.55 & 3.23 & 3.23 & 61.29 & 3.23 & 35.48 \\
\hline
\end{tabular}



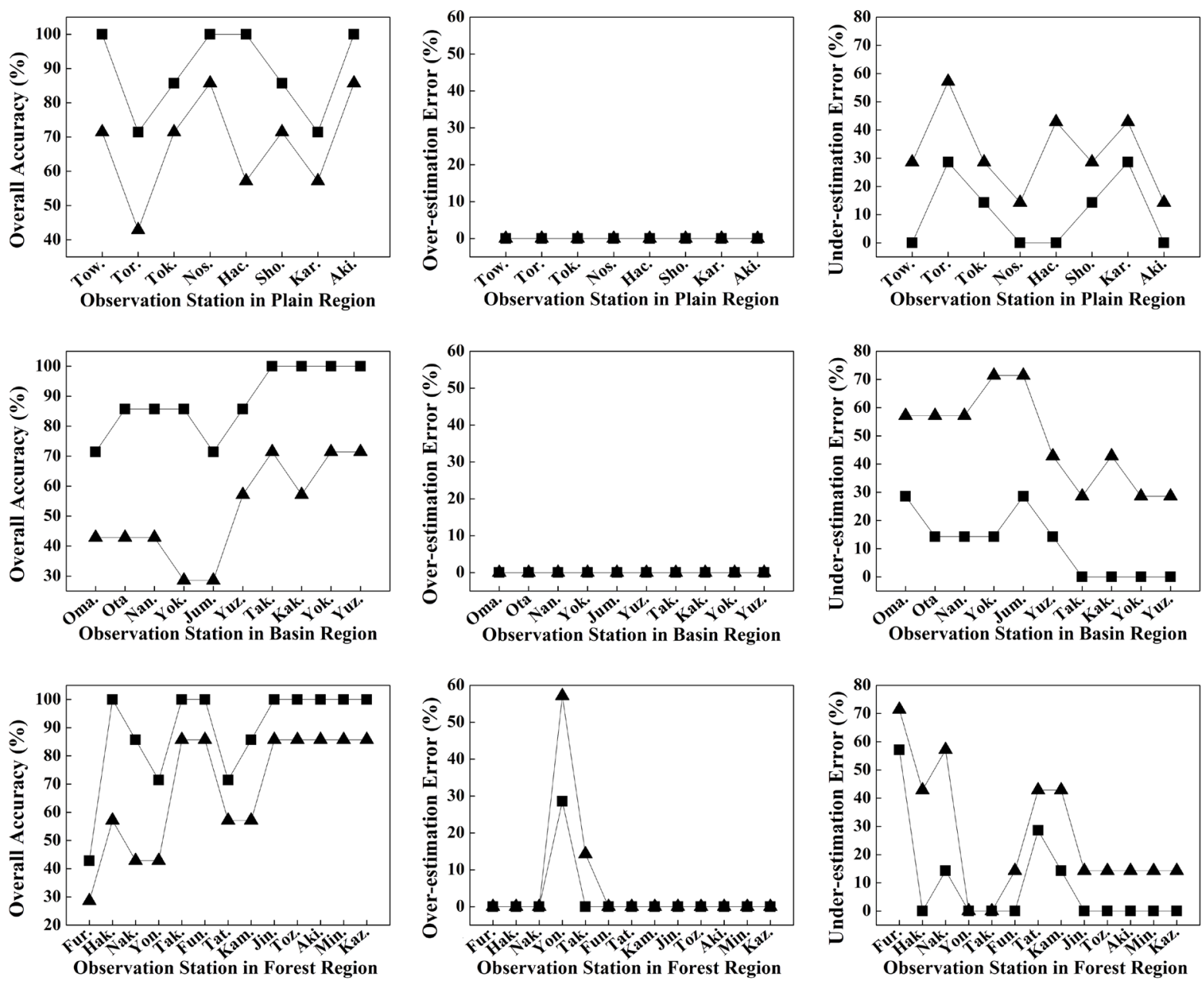

- Proposed Method

$\triangle$ MOD10_L2

Figure 8. The comparison results of the overall accuracy, over-estimation error and under-estimation error from the proposed method and the MOD10_L2 products in the study area based on the types of regions.

image data are the coarse accuracy images. One pixel represents the actual area is from several kilometers to over ten kilometers. Therefore, there are mixed pixels in forest areas; second, the ground observation data used in this work are snow depth sensor observation data. It mainly based on the location of sensors. In mixed pixels, it is only one specific position. If there is no snow cover pixel in this position, it may be also detected out as snow pixel in other position; third, the Yonaizawa observation station locates in the southeast corner of the Takanosu Basin and is adjacent to the northeast corner of the Taihei Mountains. For MOD10_L2 products, snow pixels are detected with the combination of NDSI and NDVI, the vegetation area is first recognized with NDVI, then the NDSI value is decreased to detect the snow cover pixels of forest areas. Therefore, the mixed pixels may be detected out as snow pixels wrongly. Moreover, the Takahi observation station locates in the northeast corner of the Akita Plain and is adjacent to the northwest corner of the Taihei Mountains. It belongs to coastal area. There are a lot of agricultural lands near the observation station. Therefore, the pixel may be the mixed pixel of agricultural, forest and snow.

From Figure 8, we can also know that there are many under-estimation errors of the SCD results from both the proposed method and the MOD10_L2 products in the plain, basin and forest regions. The average under-estimation error of basin areas is the largest, and the following are the plain areas and forest areas respectively. But, the errors of the proposed method are less than MOD10_L2 products, because the terrain variations in basin and plain areas are less than that in forest areas. Both the proposed method and the MOD10_L2 products have only considered the terrain variations of forest areas during the process of the SCD, so the errors of under-estimation 
in forest areas are relatively lower than the errors of under-estimation in other two types of regions. However, comparing the terrain variations of basin and plain, we can know that the terrain variations in basin areas are more than that of plain areas, which can lead to much higher errors in basin areas during the process of the SCD. In addition, the topographic correction is conducted in the proposed method, so the under-estimation error of the proposed method is lower than MOD10_L2 products. The proposed method can detect the snow cover pixels out more accurately than MOD10_L2 products. Therefore, it is feasible and effective to use the proposed method for the SCD in Akita prefecture.

\section{Conclusion}

The MODIS snow cover product (MOD10_L2) is not pre-processed by the atmospheric and topographic correction, which caused many errors for the SCD. In this work, a new SCD method based on visible red and blue channel from MODIS imagery is proposed with fully considering the influence of atmosphere, topographic features, snowcovered underlying surface and the principle of the SCD from MOD10_L2. Akita prefecture in Japan with a typical climate of the Sea of Japan as the study area is selected. MOD02HKM product sunny cloud-free data from May 2012 to April 2014 are used. In order to improve the accuracy of the SCD, the pre-processing is conducted before the SCD. It includes the geographic correction with the MRT Swath, study area clipping with the Akita administrative regional boundary ShapeFile data, atmospheric correction with the 6S code and topographic correction with a shadowing function algorithm. In order to investigate and analyze the snow cover distributions and changes around one year at different periods in the study area, the composited true color images which represents 5 types of typical snow cover distribution situations on clear days and their corresponding 2dimensional scatter plot density distribution figures in visible red band 1 and blue band 3 are selected as the training images. The threshold values of the reflectance are determined as greater than 0.458 in band 1 and greater than 0.60 in band 3 through all of situations analysis. Finally, the final SCD map is extracted according to these threshold values. In order to evaluate the effectiveness of the proposed method, the snow depth records of 31 observation stations across the whole study area are chosen and divided into three types according to their longitude and latitude locations, which are the forest region, the plain region and basin region. Meanwhile, the overall accuracy, over-estimation error and under-estimation error as the validation method are adopted and calculated. The results suggested that the overall accuracy of the proposed method is higher than the MOD10_L2 products. Therefore, it is feasible and effective to use the proposed method for the SCD in Akita Prefecture of Japan with MODIS images in order to improving the environment management and agricultural development.

\section{Acknowledgements}

This research is supported by the Akita Construction Department Road Division. We would like to express our heartfelt thanks to them for providing the Road Snow Information System data.

\section{References}

[1] Barry, R.G. (2002) The Role of Snow and Ice in the Global Climate System: A Review. Polar Geography, 26, $235-246$. http://www.tandfonline.com/doi/abs/10.1080/789610195

[2] Barry, R.G., Fallot, J.-M. and Armstrong, R.L. (1995) Twentieth-Century Variability in Snow-Cover Conditions and Approaches to Detecting and Monitoring Changes: Status and Prospects. Progress in Physical Geography, 19, 520-532. http://ppg.sagepub.com/content/19/4/520.short http://dx.doi.org/10.1177/030913339501900405

[3] Bormann, K.J., McCabe, M.F. and Evans, J.P. (2012) Satellite Based Observations for Seasonal Snow Cover Detection and Characterisation in Australia. Remote Sensing of Environment, 123, 57-71. http://www.sciencedirect.com/science/article/pii/S0034425712001228 http://dx.doi.org/10.1016/j.rse.2012.03.003

[4] Warren, S.Q. (1982) Optical Properties of Snow. Reviews of Geophysics, 20, 67-89. http://onlinelibrary.wiley.com/doi/10.1029/RG020i001p00067/abstract http://dx.doi.org/10.1029/RG020i001p00067

[5] Dozier, J. (1989) Spectral Signature of Alpine Snow Cover from the Landsat Thematic Mapper. Remote Sensing of Environment, 28, 9-22. http://www.sciencedirect.com/science/article/pii/0034425789901016 http://dx.doi.org/10.1016/0034-4257(89)90101-6 
[6] Harrison, A.R. and Lucas, R.M. (1989) Multi-Spectral Classification of Snow Using NOAA AVHRR Imagery. International Journal of Remote Sensing, 10, 907-916. http://www.tandfonline.com/doi/abs/10.1080/01431168908903930?journalCode=tres20 http://dx.doi.org/10.1080/01431168908903930

[7] Hall, D.K., Riggs, G.A. and Salomonson, V.V. (1995) Development of Methods for Mapping Global Snow Cover Using Moderate Resolution Imaging Spectroradiometer (MODIS) Data. Remote Sensing of Environment, 54, 127-140. http://www.sciencedirect.com/science/article/pii/003442579500137P http://dx.doi.org/10.1016/0034-4257(95)00137-P

[8] Hall, D.K., Riggs, G.A., Salomonson, V.V., DiGirolamo, N.E. and Bayr, K.J. (2002) MODIS Snow-Cover Products. Remote Sensing of Environment, 83, 181-194. http://www.sciencedirect.com/science/article/pii/S0034425702000950

[9] Dietz, A.J., Kuenzer, C., Gessner, U. and Dech, S. (2012) Remote Sensing of Snow—A Review of Available Methods. International Journal of Remote Sensing, 33, 4094-4134.

http://www.tandfonline.com/doi/abs/10.1080/01431161.2011.640964\#.VJfVkshIA http://dx.doi.org/10.1080/01431161.2011.640964

[10] Hall, D.K. and Riggs, G.A. (2007) Accuracy Assessment of the MODIS Snow Products. Hydrological Processes, 21, 1534-1547. http://onlinelibrary.wiley.com/doi/10.1002/hyp.6715/abstract http://dx.doi.org/10.1002/hyp.6715

[11] Salomonson, V.V. and Appel, I. (2004) Estimating Fractional Snow Cover from MODIS Using the Normalized Difference Snow Index. Remote Sensing of Environment, 89, 351-360. http://www.sciencedirect.com/science/article/pii/S0034425703002864 http://dx.doi.org/10.1016/j.rse.2003.10.016

[12] Pan, P.P., Saruta, K., Terata, Y. and Chen, G.Y. (2014) Observations for Snow Cover Detection in Akita via the Combination of Normalized Difference Vegetation Index and Normalized Difference Snow Index. Transactions of the Japan Society for Aeronautical and Space Sciences, Aerospace Technology Japan, 12, 1-7. https://www.jstage.jst.go.jp/article/tastj/12/ists29/12_Pn_1/_article

[13] Department of Agriculture, Forestry and Fisheries (2014) Summary of Forest and Forestry in Akita Report 2012-2014. http://www.pref.akita.lg.jp/www/contents/1152763039710/files/H26gaiyou.pdf

[14] Hall, D.K., Riggs, G.A. and Salomonson, V.V. (2001) Algorithm Theoretical Basis Document (ATBD) for the MODIS Snow and Sea Ice-Mapping Algorithms. http://modis.gsfc.nasa.gov/data/atbd/atbd mod10.pdf

[15] Toutin, T. (2002) Impact of Terrain Slope and Aspect on Radargrammetric DEM Accuracy. ISPRS Journal of Photogrammetry and Remote Sensing, 57, 228-240. http://www.sciencedirect.com/science/article/pii/S0924271602001235 http://dx.doi.org/10.1016/S0924-2716(02)00123-5

[16] Land Processes Distributed Active Archive Center and USGS Earth Resources Observation and Science Center (2010) MODIS Reprojection Tool Swath User Manual Release 2.2.

[17] Kotchenova, S.Y., Vermote, E.F., Matarrese, R. and Klemm, F.J. (2006) Validation of a Vector Version of the 6S Radiative Transfer Code for Atmospheric Correction of Satellite Data. Part I: Path Radiance. Applied Optics, 45, 67626774. http://www.opticsinfobase.org/ao/abstract.cfm?uri=ao-45-26-6762

[18] Kotchenova, S.Y. and Vermote, E.F. (2007) Validation of a Vector Version of the 6S Radiative Transfer Code for Atmospheric Correction of Satellite Data. Part II. Homogeneous Lambertian and Anisotropic Surfaces. Applied Optics, 46, 4455-4464. http://www.opticsinfobase.org/ao/abstract.cfm?uri=ao-46-20-4455

[19] Dubayah, R. (1992) Estimating Net Solar Radiation Using Landsat Thematic Mapper and Digital Elevation Data. Water Resources Research, 28, 2469-2484. http://onlinelibrary.wiley.com/doi/10.1029/92WR00772/abstract http://dx.doi.org/10.1029/92WR00772

[20] Hapke, B. (1984) Bidirectional Reflectance Spectroscopy: 3. Correction for Macroscopic Roughness. Icarus, 59, 41-59. http://www.sciencedirect.com/science/article/pii/001910358490054X http://dx.doi.org/10.1016/0019-1035(84)90054-X

[21] Liang, S.L. (2003) Quantitative Remote Sensing of Land Surfaces. Wiley-Interscience, Hoboken. http://dx.doi.org/10.1002/047172372X 
Scientific Research Publishing (SCIRP) is one of the largest Open Access journal publishers. It is currently publishing more than 200 open access, online, peer-reviewed journals covering a wide range of academic disciplines. SCIRP serves the worldwide academic communities and contributes to the progress and application of science with its publication.

Other selected journals from SCIRP are listed as below. Submit your manuscript to us via either submit@scirp.org or Online Submission Portal.
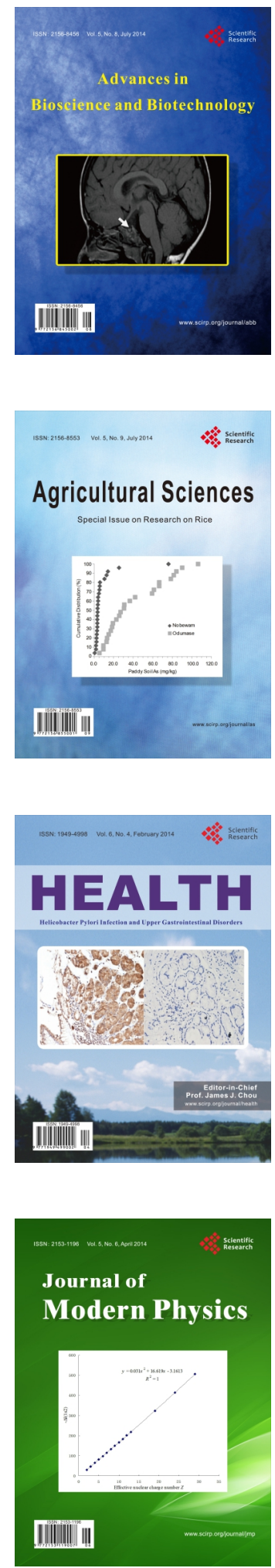
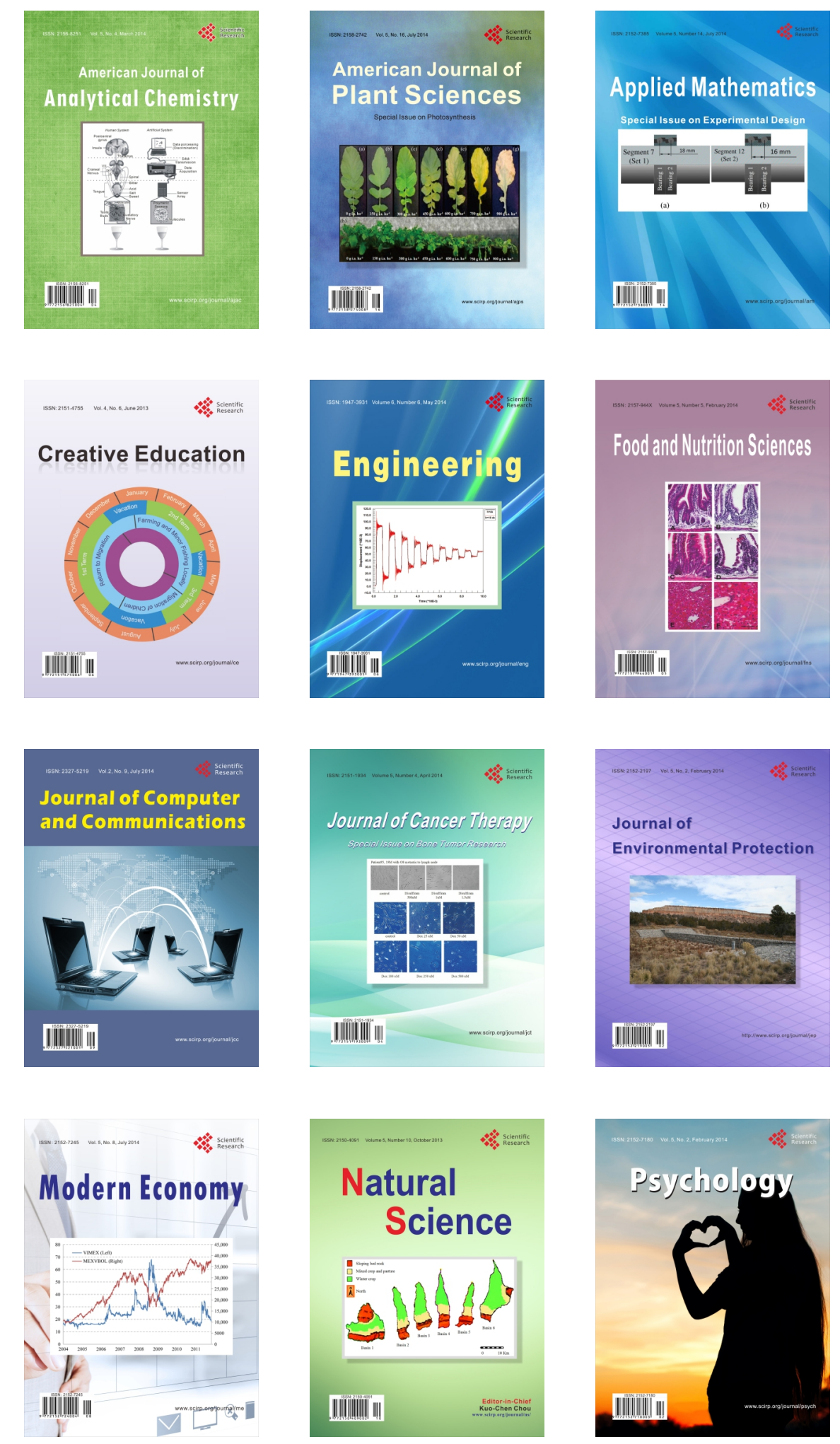